\title{
Lung transplantation with lungs from donors fifty years of age and older
}

\author{
Stefan Fischer, MD, MSc ${ }^{a}$ \\ Bernhard Gohrbandt, MD ${ }^{\mathrm{a}}$ \\ Pascal Struckmeier, MS ${ }^{a}$ \\ Jost Niedermeyer, MD ${ }^{\mathrm{b}}$ \\ Andre Simon, $M D^{\mathrm{a}}$ \\ Christian Hagl, MD ${ }^{\mathrm{a}}$ \\ Klaus Kallenbach, $\mathrm{MD}^{\mathrm{a}}$ \\ Axel Haverich, MD \\ Martin Strüber, $\mathrm{MD}^{\mathrm{a}}$
}

\footnotetext{
From the Hannover Thoracic Transplant Program, Division of Thoracic- and Cardiovascular Surgery, ${ }^{\mathrm{a}}$ and Department of Respiratory Medicine, ${ }^{\mathrm{b}}$ Hannover Medical School, Hannover, Germany.

Presented at the Twenty-fourth Annual Meeting of the International Society for Heart and Lung Transplantation (ISHLT), 2004, San Francisco, Calif.

Received for publication April 14, 2004; revisions received July 26, 2004; accepted for publication July 28, 2004.

Address for reprints: Martin Strüber, MD, Director, Hannover Thoracic Transplant Program, Division of Cardiothoracic and Vascular Surgery, Hannover Medical School, Carl-Neuberg-Strasse 1, Hannover, 30625, Germany (E-mail: strueber@ thg.mh-hannover.de).

J Thorac Cardiovasc Surg 2005;129:919-25 $0022-5223 / \$ 30.00$

Copyright (c) 2005 by The American Association for Thoracic Surgery

doi:10.1016/j.jtcvs.2004.07.053
}

Background: A shortage of donors has led to the progressive expansion of criteria for donor selection in lung transplantation. The outcome of recipients of lungs from donors aged 50 years or older is analyzed systematically.

Methods: From March 1998 to June 2003, 49 recipients received lungs from donors aged 50 years or older (range 50-64 years, mean $54 \pm 3$ years). This group of recipients was compared with 244 patients receiving lungs from donors aged less than 50 years (range 7-49 years, mean $32 \pm 11$ years). This study was undertaken on all 293 patients at our institution who received Perfadex-preserved lungs (Vitrolife, Göteborg, Sweden).

Results: Recipient age, sex, and indications for transplant did not differ significantly between groups. Also, the percentage of the different types of transplants (bilateral or single lung transplantation) performed was equal in both cohorts. Donor $\mathrm{PaO}_{2} /$ $\mathrm{FIO}_{2}$ ratios before lung retrieval ( $415 \pm 91$ vs $439 \pm 113$, respectively) and length of ischemic time ( $347 \pm 67$ minutes vs $351 \pm 84$ minutes, respectively) did not differ significantly between the older and younger donor groups. The following posttransplant parameters were also not statistically different: first $\mathrm{PaO}_{2} / \mathrm{FiO}_{2}$ at intensive care unit arrival ( $274 \pm 125$ in the older donor group vs $253 \pm 119$ in the younger donor group, respectively), mechanical ventilation time (328 \pm 427 hours vs $269 \pm 425$ hours, respectively), and length of stay in the intensive care unit (16 \pm 18 days vs $14 \pm 18$ days, respectively). Recipient survival in the older and younger donor groups at 30 days, $3,6,12,24$, and 60 months was $77 \% \pm 6 \%, 75 \%$ $\pm 6 \%, 73 \% \pm 7 \%, 73 \% \pm 7 \%, 68 \% \pm 5 \%$, and $68 \% \pm 4 \%$ versus $86 \% \pm 2 \%, 83 \%$ $\pm 3 \%, 80 \% \pm 3 \%, 78 \% \pm 3 \%, 71 \% \pm 4 \%$, and $66 \% \pm 4 \%$, respectively.

Conclusions: Lung grafts from elderly donors have been considered as marginal organs for transplantation. However, this study indicates that transplantation of lungs from carefully selected donors aged 50 years or more may lead to similar short- and long-term outcomes compared with lungs from younger donors. The use of lungs from elderly donors may help to increase the number of donor organs in lung transplantation.

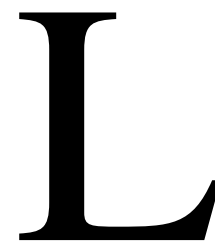

ung transplantation has evolved during the past 2 decades to become a viable treatment option for several end-stage pulmonary diseases. ${ }^{1}$ Although the number of annually performed lung transplant procedures still increases, ${ }^{2}$ donor organ availability has become a serious problem, and the demand for donor lungs clearly exceeds the supply. This lack of donor organs has led to an increasing mortality of patients on the lung transplant waiting list. Obviously, the risk of mortality by the 
TABLE 1. Donor characteristics

\begin{tabular}{lcc}
\hline & $\begin{array}{c}\text { Do }<50 \text { group } \\
(\mathbf{n}=\mathbf{2 4 4 )}\end{array}$ & $\begin{array}{c}\text { Do }>\mathbf{5 0} \text { group } \\
(\mathbf{n}=\mathbf{4 9})\end{array}$ \\
\hline $\begin{array}{l}\text { Age (y) } \dagger \\
\text { Female donors }(\mathrm{n})^{*}\end{array}$ & $32 \pm 11(7-49)$ & $54 \pm 3(50-64)$ \\
Cause of death $(\mathrm{n})^{*}$ & $96(39 \%)$ & $27(55 \%)$ \\
$\quad$ Intracerebral hemorrhage* & $111(46 \%)$ & $36(74 \%)$ \\
$\quad$ Cerebral hypoxia & $20(8 \%)$ & $5(10 \%)$ \\
$\quad$ Tumor & $2(1 \%)$ & 0 \\
$\quad$ Head injury* & $104(43 \%)$ & $8(16 \%)$ \\
$\quad$ Other & $5(2 \%)$ & 0 \\
Ventilation time before & $3.7 \pm 3.6$ & $3.5 \pm 2.9$ \\
$\quad$ harvest (d) & $439 \pm 113$ & $415 \pm 91$ \\
Final Pa0 ${ }_{2}$ before harvest & & \\
$\quad$ (mm Hg) & $351 \pm 84$ & $347 \pm 67$ \\
Total ischemic time (min) & $14(6 \%)$ & $5(10 \%)$ \\
Positive smoking history (n) & & \\
\hline$D o<50$, Donors aged less than 50 years; Do $>50$, donors aged 50 years \\
or more.
\end{tabular}

length of waiting time is not equal among the different indications for lung transplantation. However, for cystic fibrosis and interstitial pulmonary fibrosis, Hosenpud and associates $^{3}$ showed a waiting list mortality of $25 \%$ to $30 \%$ and $40 \%$ to $45 \% 1$ and 2 years after listing, respectively.

Several concepts to increase the number of donor organs in lung transplantation have been mentioned. Some are still more experimental in nature such as pulmonary xenotransplantation ${ }^{4}$ or the implantation of tissue-engineered bioartificial lungs, ${ }^{5}$ whereas others have been clinically tested in single cases such as the use of lungs from non-heartbeating donors. ${ }^{6}$ Living-related lung or lobar transplantation has been applied in single and specialized centers only, but has achieved promising outcome there. ${ }^{7}$

Another concept to overcome the shortage of donor organs is the use of lungs from so-called marginal donors, who do not fulfill the commonly accepted lung donor criteria and, thus, are usually not offered or accepted for lung transplantation. Pierre and coworkers ${ }^{8}$ published a first major report on their experience in using marginal donor lungs in lung and heart-lung transplantation. They focused on the short-term and midterm outcomes after transplantation of 63 extended donor lungs and compared those with the outcome of 60 lung transplants with lungs from standard donors. In that study donors were considered "marginal" when one of the following criteria was met: (1) purulent bronchoscopic findings, (2) $\mathrm{PaO}_{2}$ less than $300 \mathrm{~mm} \mathrm{Hg}$, (3) occurrence of an infiltrate on chest radiography, (4) active smoker ( $>20$ pack-years), or (4) donor aged 55 years or more. Although the 30-day mortality was significantly higher in the extended donor group compared with standard donors, donor-
TABLE 2. Recipient characteristics

\begin{tabular}{|c|c|c|}
\hline & $\begin{array}{c}\text { Do }<50 \text { group } \\
(n=244)\end{array}$ & $\begin{array}{c}\text { Do }>50 \text { group } \\
(n=49)\end{array}$ \\
\hline Age (y) & $41 \pm 13(13-66)$ & $42 \pm 13(16-64)$ \\
\hline \multicolumn{3}{|l|}{$\operatorname{Sex}(n)$} \\
\hline Male & $136(56 \%)$ & $24(49 \%)$ \\
\hline Female & $108(44 \%)$ & $25(51 \%)$ \\
\hline \multicolumn{3}{|l|}{ Indication for transplant (n) } \\
\hline Emphysema & $82(37 \%)$ & $13(27 \%)$ \\
\hline Idiopathic pulmonary fibrosis & $56(23 \%)$ & $16(33 \%)$ \\
\hline Cystic fibrosis & $56(23 \%)$ & $7(14 \%)$ \\
\hline $\begin{array}{l}\text { Primary pulmonary } \\
\text { hypertension }\end{array}$ & $11(5 \%)$ & $3(6 \%)$ \\
\hline Lymphangioleiomyomatosis & $3(1 \%)$ & $1(2 \%)$ \\
\hline Sarcoidosis & $6(3 \%)$ & $1(2 \%)$ \\
\hline $\begin{array}{l}\text { Redo-transplant for chronic } \\
\text { graft failure (BOS) }\end{array}$ & $19(8 \%)$ & $7(14 \%)$ \\
\hline Other & $11(5 \%)$ & $1(2 \%)$ \\
\hline \multicolumn{3}{|l|}{ Type of transplant (n) } \\
\hline Single lung transplant & $42(17 \%)$ & $6(12 \%)$ \\
\hline Bilateral lung transplant & $202(83 \%)$ & $43(88 \%)$ \\
\hline $\begin{array}{l}\text { “High urgency" status on } \\
\text { waiting list }(n)\end{array}$ & $56(23 \%)$ & $14(29 \%)$ \\
\hline
\end{tabular}

BOS, Bronchiolitis obliterans syndrome; $D o<50$, donors aged less than 50 years; $D o>50$, donors aged 50 years or more.

$P<.05$.

related death occurred in only $50 \%$ of all deaths in that group. Thus, the authors concluded that although many extended donor lungs will result in acceptable postoperative function, extended donors should be carefully selected because there seems to be an increased early mortality rate in that group of recipients.

We believe that with their first publication on extended donors, the Toronto group ${ }^{8}$ has made an important step toward reflecting on the commonly accepted lung donor criteria to increase the pool of transplantable donor organs. However, in their analysis the number of patients in the different extended criteria subgroups was small, and statistical analysis was performed on the total number of extended donor transplants. It is possible that the impact of purulent secretion in donor lungs, for example, on posttransplant outcome is different from that of donor age. Therefore, in our study we picked only 1 criterion, donor age, for extended donors according to Pierre and coworkers $^{8}$ and systematically reviewed our experience with transplantation of lungs from donors 50 years of age and older.

\section{Methods}

Between March 10, 1998, and June 30, 2003, data were prospectively recorded for 293 patients who underwent lung transplantation at the Hannover Thoracic Transplant Program of the Hannover Medical School. This time period was chosen because we 
TABLE 3. Outcome after lung transplantation

\begin{tabular}{|c|c|c|}
\hline & $\begin{array}{c}\text { Do }<50 \text { group } \\
(n=244)\end{array}$ & $\begin{array}{c}\text { Do }>50 \text { group } \\
(n=49)\end{array}$ \\
\hline $\begin{array}{l}\text { Length of post-LTx } \\
\text { ventilation (hr) }\end{array}$ & $269 \pm 425$ & $328 \pm 427$ \\
\hline Length of ICU stay (d) & $14 \pm 18$ & $16 \pm 18$ \\
\hline \multicolumn{3}{|l|}{ Survival $(\%)$} \\
\hline $30 \mathrm{~d}$ & $86 \pm 2$ & $77 \pm 6$ \\
\hline $3 \mathrm{mo}$ & $83 \pm 3$ & $75 \pm 6$ \\
\hline $6 \mathrm{mo}$ & $80 \pm 3$ & $75 \pm 7$ \\
\hline $12 \mathrm{mo}$ & $78 \pm 3$ & $73 \pm 7$ \\
\hline $2 y$ & $71 \pm 4$ & $68 \pm 5$ \\
\hline $5 y$ & $66 \pm 4$ & $68 \pm 4$ \\
\hline First $\mathrm{PaO}_{2} / \mathrm{FlO}_{2}$ on the ICU & $253 \pm 119$ & $274 \pm 125$ \\
\hline $\begin{array}{l}\text { Cause of death after } \\
\text { LTx (n) }\end{array}$ & $60(25 \%)$ & $15(31 \%)$ \\
\hline Acute graft failure & $7(12 \%$ of deaths $)$ & $2(13 \%$ of deaths $)$ \\
\hline Chronic graft failure & $1(2 \%)$ & 0 \\
\hline $\begin{array}{l}\text { Sepsis/multiorgan } \\
\text { failure }\end{array}$ & $22(37 \%)$ & $7(47 \%)$ \\
\hline Bronchial complications & $6(10 \%)$ & $1(7 \%)$ \\
\hline $\begin{array}{l}\text { Cardiac/hemodynamic } \\
\text { complications }\end{array}$ & $4(8 \%)$ & $1(7 \%)$ \\
\hline $\begin{array}{l}\text { Neurologic } \\
\text { complications }\end{array}$ & $3(5 \%)$ & $2(13 \%)$ \\
\hline $\begin{array}{l}\text { Gastroenterologic } \\
\text { complications }\end{array}$ & $6(10 \%)$ & 0 \\
\hline Neoplasia & $2(3 \%)$ & 0 \\
\hline Unknown & $9(15 \%)$ & $2(13 \%)$ \\
\hline
\end{tabular}

Do $<50$, Donors aged less than 50 years; $D o>50$, donors aged 50 years or more; $I C U$, intensive care unit; $L T x$, lung transplantation.

$P<.05$.

switched our lung-preservation strategy in our clinical lung transplant program on March 10, 1998, from the use of an intracellulartype preservation solution (Euro-Collins) to an extracellular-type preservation solution (Perfadex, Vitrolife, Göteborg, Sweden), ${ }^{9}$ and therefore included all patients at our program with Perfadexpreserved lungs in this study. Data were analyzed retrospectively. In this study patients were divided into 2 groups: donors aged less than 50 years $($ Do $<50)$ and donors aged 50 years or older $($ Do $>$ 50).

All donors were assessed for acceptability for transplantation by the retrieving lung transplant fellow or staff lung transplant surgeon from our program. No lungs were harvested by surgeons from other programs. Donor lungs were assessed by bronchoscopy, laboratory work, and medical history. Macroscopic inspection of the lung was finally performed by the retrieving surgeon. As mentioned previously, a low-potassium dextran solution (Perfadex) was used for lung preservation. ${ }^{10}$ Lung function before harvest was based on the final $\mathrm{PaO}_{2} / \mathrm{FIO}_{2}$ ratio in the operating room. Although some donors showed initial $\mathrm{PaO}_{2} / \mathrm{FIO}_{2}$ ratios less than 300, all donor lungs showed $\mathrm{PaO}_{2} / \mathrm{FIO}_{2}$ ratio greater than 300 after extended donor resuscitation and specific management including adjustment of mechanical ventilation and performance of bronchoscopy. Donors with clear signs for aspiration or mucus

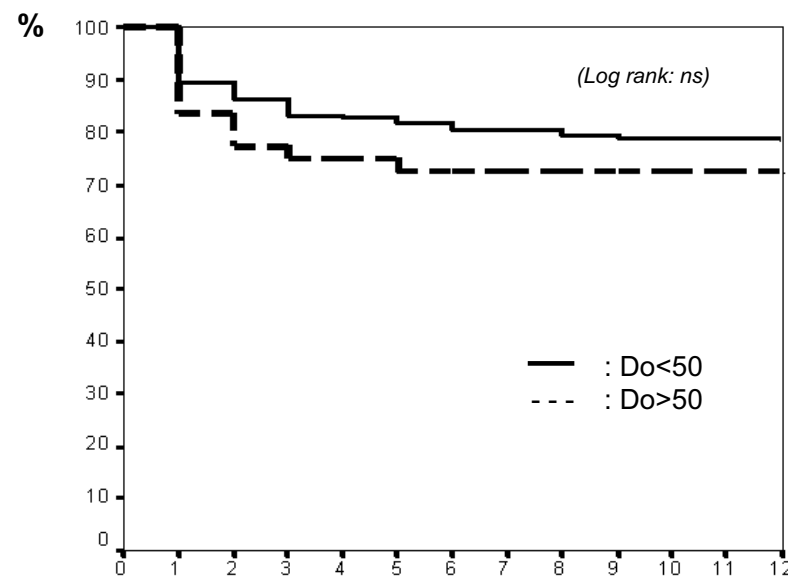

months after lung transplantation

Figure 1. Survival during the first year after lung transplantation in group comparison. (Do < 50, donors aged less than 50 years; Do $>$ 50, donors aged 50 years or more.)

accumulation that could not be suctioned clear as well as organs with significant tissue traumatization or lung infiltration on radiography were rejected for transplantation, regardless of the age of the donor. Fluid accumulation was restricted to maintain euvolemia to avoid fluid overload and, consequently, lung edema. One gram of prednisone was administered to the donor between the initial contact with the donor hospital and arrival of the harvesting surgical team.

The primary end point in this study was 1-year survival. A second major end point was initial graft function as assessed by the initial $\mathrm{PaO}_{2} / \mathrm{FIO}_{2}$ ratio at arrival on the cardiothoracic intensive care unit (ICU). Secondary end points included 30-day, 3-, 6-, 24-, and 60 -month survival, donor and recipient gender and age, donor smoking history, donor cause of death, type of transplant (single vs bilateral lung transplant), indication for lung transplantation, length of posttransplant mechanical ventilatory support, and duration of ICU stay. It was also recorded whether a patient had a preoperative "high urgency" status on the waiting list because of rapid progression of the pulmonary disease with need for intensive care treatment or even mechanical ventilatory support.

The software package SPSS 11.0 for Windows (SPSS Inc, Chicago, Ill) was used for statistical analysis. Group comparison was performed with the unpaired $t$ test for continuous variables or the $\chi^{2}$ test for categorical variables. The Wilcoxon and log-rank test were used for statistical analysis of patient survival. A Cox regression analysis was performed to test the impact of ischemic time and donor age on posttransplant survival days. Data are presented as means $\pm \mathrm{SD}$.

\section{Results}

Of the 293 patients included in this study, 244 patients received lungs from donors aged less than 50 years (donor age: $32 \pm 11$ years, range: 7-49 years). Forty-nine patients underwent transplantation with lungs from donors aged 50 years or less (donor age: $54 \pm 3$ years, range: 50-64 years). 
TABLE 4. Outcome after lung transplantation by different age subgroups in the elderly donor cohort (Do > 50)

\begin{tabular}{|c|c|c|c|}
\hline & $\begin{array}{c}\text { Do } 50-54 \text { y } \\
(\mathrm{n}=31)\end{array}$ & $\begin{array}{c}\text { Do } 55-59 \text { y } \\
\text { (n = 12) }\end{array}$ & $\begin{array}{c}\text { Do }>59 y \\
(n=6)\end{array}$ \\
\hline Length of post-LTx ventilation (hr) & $364 \pm 450$ & $307 \pm 452$ & $303 \pm 221$ \\
\hline Length of ICU stay $(d)$ & $18 \pm 20$ & $14 \pm 19$ & $7 \pm 9$ \\
\hline \multicolumn{4}{|l|}{ Survival $(\%)$} \\
\hline $30 \mathrm{~d}$ & $90 \pm 2$ & $82 \pm 3$ & $75 \pm 3$ \\
\hline $3 \mathrm{mo}$ & $81 \pm 2$ & $73 \pm 2$ & $75 \pm 3$ \\
\hline $6 \mathrm{mo}$ & $71 \pm 1$ & $73 \pm 2$ & $75 \pm 3$ \\
\hline 12 mo & $71 \pm 1$ & $73 \pm 2$ & $75 \pm 3$ \\
\hline First $\mathrm{PaO}_{2} / \mathrm{FIO}_{2}$ on the ICU & $282 \pm 138$ & $261 \pm 151$ & $262 \pm 113$ \\
\hline Best FEV $_{1}\left(\%\right.$ of predicted $\left.\mathrm{FEV}_{1}\right)$ & $73 \pm 22$ & $80 \pm 18$ & $87 \pm 32$ \\
\hline Cause of death after LTx (n) & $10(32 \%)$ & $4(36 \%)$ & $1(25 \%)$ \\
\hline Acute graft failure & $1(11 \%$ of deaths $)$ & $1(25 \%$ of deaths) & 0 \\
\hline Chronic graft failure & $1(11 \%)$ & 0 & 0 \\
\hline Sepsis/multiorgan failure & $4(44 \%)$ & $3(75 \%)$ & 0 \\
\hline Bronchial complications & $1(11 \%)$ & 0 & 0 \\
\hline Cardiac/hemodynamic complications & $1(11 \%)$ & 0 & 0 \\
\hline Neurologic complications & $1(11 \%)$ & 0 & $1(100 \%)$ \\
\hline Gastroenterologic complications & 0 & 0 & 0 \\
\hline Neoplasia & 0 & 0 & 0 \\
\hline Unknown & $1(11 \%)$ & 0 & 0 \\
\hline
\end{tabular}

$D o>50$, Donors aged 50 years or more; $L T X$, lung transplantation; $I C U$, intensive care unit; $F E V_{1}$, forced expiratory volume in 1 second. $P<.05$.

Table 1 compares several donor-related variables between the 2 groups. The mean donor age was significantly older in the group of elderly donors $(P<.001)$. The length of mechanical ventilation before harvest did not differ significantly among groups with $3.5 \pm 2.9$ days in the Do $>50$ cohort and $3.7 \pm 3.6$ days in the Do $<50$ cohort. In addition, donor pulmonary function before lung retrieval as assessed by $\mathrm{PaO}_{2} / \mathrm{FIO}_{2}$ at mechanical ventilation with an $\mathrm{FIO}_{2}$ of 1.0 and a positive end-expiratory pressure of $5 \mathrm{~cm} \mathrm{H}_{2} \mathrm{O}$ was also not statistically different among groups (Do $>50$ : $415 \pm 91$ vs Do < 50: $439 \pm 113$ ). With regard to donor cause of death, a significant difference was seen between groups. It is interesting that the occurrence of intracerebral hemorrhage apparently becomes the predominant cause of donor death with increasing donor age. In the Do $>50$ group, $74 \%$ of donors died of intracerebral hemorrhage versus $46 \%$ of donors in the Do $<50$ group. However, in the younger donor cohort $43 \%$ died of head injury, whereas in the elderly group of donors only $16 \%$ experienced head injury. With respect to smoking history, only incomplete or no data are often available at the time of multiorgan donor allocation. Therefore, in this study the individual smoking history was comprehensible for only $22 \%$ of patients at the time of organ retrieval. In consideration of this limitation, a positive smoking history was known for $10 \%(n=5 / 49)$ of patients in the Do $>50$ and for $6 \%(n=14 / 243)$ of patients in the Do $<50$ group. The total length of graft ischemic time between groups also was not statistically different with
$347 \pm 67$ minutes in the Do $>50$ group and $351 \pm 84$ minutes in the Do $<50$ group.

There were 48 single lung transplants and 245 bilateral lung transplants performed in the total cohort. The number of single lung and bilateral lung transplant procedures performed in the Do $>50$ group was $n=6(12 \%)$ and $n=43$ $(88 \%)$, respectively, and $n=42(17 \%)$ and $n=202(83 \%)$ in the Do $<50$ group, respectively. Table 2 shows recipient characteristics including the indications for lung transplantation.

Table 3 summarizes the outcome after lung transplantation among groups regarding several end points. The 30day, 3-, 6-, 24-, and 60-month survival was 77\% $\pm 6 \%$, $75 \% \pm 6 \%, 73 \% \pm 7 \%, 68 \% \pm 5 \%$, and $68 \% \pm 4 \%$ in the Do $>50$ group compared with $86 \% \pm 2 \%, 83 \% \pm 3 \%$, $80 \% \pm 3 \%, 71 \% \pm 4 \%$, and $66 \% \pm 4 \%$ in the Do $<50$ group, respectively, which did not show statistical differences. The primary end point, 1-year survival, did not show a significant difference between groups, with $73 \% \pm 7 \%$ $($ Do $>50)$ and $78 \% \pm 3 \%($ Do $<50)($ Figure 1$)$. The initial graft function as assessed by the first $\mathrm{PaO}_{2} / \mathrm{FIO}_{2}$ at arrival to the ICU was not different between groups with $274 \pm 125$ and $253 \pm 119$, respectively. The different causes of death in both groups are also summarized in Table 3.

In addition, a subanalysis on the Do $>50$ group was performed with regard to age. Therefore, patients were subdivided into 3 groups: (1) donors aged 50 to 54 years, (2) donors aged 55 to 59 years, and (3) donors aged more than 
59 years. Although in the literature lung donors aged more than 50 years have frequently been considered as extended donors, it is possible that the clinically relevant cutoff point for donor age is more than 50 years. However, as shown in Table 4, the clinical outcome was not statistically different among the 3 subgroups.

A significant number of the "high urgency" candidates, which are indicated in Table 2, required pretransplant mechanical ventilatory support before lung transplantation because of rapid deterioration of their lung function. This, however, is a widely known risk factor for posttransplant survival, as repeatedly underlined in the annual report of the International Society for Heart and Lung Transplantation (ISHLT) registry. ${ }^{11}$ In previous data analyses at our institution we also showed that a pretransplant "high urgency" status on the waiting list significantly increases the risk for posttransplant mortality. Therefore, in a second subanalysis we excluded all "high urgency" patients in both study groups and found a 1-year survival of $74 \% \pm 8 \%$ in the Do $>50$ group and $78 \% \pm 3 \%$ in the Do $<50$ cohort (no significant difference), which also was not different from the overall survival in groups. The percentage of "high urgency" candidates was $23 \%$ in the younger donor group and even higher in the elderly donor cohort (29\%) (Table 2).

It was reported in the literature that elderly lung grafts may show diminished "functional reserve," which could lead to poor posttransplant graft function. ${ }^{12}$ This is certainly biologically valid; however, it has never been shown in lung function studies in elderly grafts after transplantation. We compared the portions of the predicted 1-second forced expiratory volumes $\left(\mathrm{FEV}_{1}\right)$ in both groups at 2 and 4 weeks as well as 3, 6, 9, and 12 months after lung transplantation and found that the 2 curves were almost identical among groups. Furthermore, we compared the best $\mathrm{FEV}_{1}$ values in groups during the first year after transplantation. Once again, the results were not statistically different among groups, with $79 \% \pm 22 \%$ in the Do $<50$ group and $76 \% \pm$ $22 \%$ of predicted $\mathrm{FEV}_{1}$ in the elderly donor group $(P=.2)$. These data indicate that, especially in the very early perioperative period, the functional reserve of the elderly grafts was not diminished in comparison with that of the grafts in the Do $<50$ group.

\section{Discussion}

The imbalance between the number of patients listed for a lung transplantation and the number of available donor organs has led to extended waiting times and, ultimately, to a significant mortality on the waiting list. ${ }^{13}$ Consequently, novel strategies have been discussed and partially introduced into clinical lung transplantation to increase the number of suitable donor organs. A first and reasonable step was the idea of extending the currently accepted criteria for donor selection. Many programs have begun to use mar- ginal or extended donors after reports suggesting equivalent outcomes. The Toronto group 8 published a retrospective review on 128 consecutive lung and heart/lung transplants, of which $51 \%$ were grafts retrieved from "extended donors." In that study by Pierre and colleagues, ${ }^{8}$ donors were considered "extended" if one of the following criteria was met: age more than 55 years, smoking history more than 20 pack-years, presence of chest radiographic film infiltrate, $\mathrm{PaO}_{2}$ less than $300 \mathrm{~mm} \mathrm{Hg}$ before lung retrieval, or purulent secretions on pre-retrieval bronchoscopy. They concluded that caution should be exercised in the use of certain extended donor lungs, because there seems to be an increased early mortality rate in that group of recipients, although many extended donor lungs will result in acceptable postoperative function. This particular finding underlines the need for further studies to clearly identify the new borderline to which donor lungs can be accepted for transplantation with a reasonable chance for successful outcome and below which, on the other hand, lungs should probably not be accepted for transplantation. This study further suggests different donor variables such as donor age, bronchoscopic and radiography findings, time of ventilation before organ retrieval, and smoking history, each of which can identify a donor as a "marginal" donor and could possibly be extended to increase the number of transplantable donor organs. It has become a novel standard that the ISHLT discusses the issue of redefining currently accepted lung donor criteria and the concept of using marginal donor organs for selected recipients in a main session at the Society's annual meeting. In a consensus report from the Pulmonary Council of the ISHLT, Orens and associates ${ }^{12}$ extendedly reviewed the currently accepted lung transplant donor acceptability criteria. Therefore, they reviewed the evidence in the literature regarding 13 major risk factors for outcome after lung transplantation. With regard to the impact of donor age on lung transplant outcome, they repeatedly underlined a possible negative interaction between donor age and graft ischemic time. ${ }^{12}$ Novick and associates ${ }^{14}$ found that lung donor age less than 10 years or more than 50 years may be associated with an increase in posttransplant mortality according to data derived from patients who were reported to the United Network for Organ Sharing (UNOS) and ISHLT registry between 1987 and 1997 . Therefore, in our study we chose 50 years as the donor age limit between both study groups. The negative interaction between donor age and ischemic time as described by Novick and colleagues, however, could not be confirmed in a large, recently published multivariate analysis by the Eurotransplant International Foundation in Leiden (The Netherlands) and coinvestigators on 590 consecutive lung transplants, which were performed between 1997 and 1999 at 21 Eurotransplant centers. ${ }^{15}$ Certainly, the largest data set on patient outcome after lung transplantation is the ISHLT registry. ${ }^{2}$ In the 18 th report on 
the registry, an interaction between a center's volume of annually performed lung transplant procedures and donor age was described. Odds ratios changed from $0.57,1.16$, to 2.37 in centers performing 55, 30, and 5 lung transplants per year, respectively, with a donor age of 60 years. ${ }^{16}$ This possible association between center lung transplant volume and lung survival, however, was not supported by data from the Eurotransplant analysis. ${ }^{15}$

Except for reports on singular cases or small patient cohorts, the literature does not provide sufficient evidence regarding the impact of donor age on lung transplantation outcome. As summarized in the ISHLT Pulmonary Council report, smaller studies have not shown a survival disadvantage with the use of elderly donors, ${ }^{17,18}$ but larger registry studies such as the ISHLT registry report or the study by Novick and associates have indicated a negative effect on survival, particularly when combined with increased graft ischemic time. ${ }^{14,16}$

In 1998, a significant change in clinical lung transplantation occurred with the introduction by us and others ${ }^{9,10}$ of Perfadex preservation solution, which is based on an extracellular-type low-potassium dextran solution. Since that time, increasing numbers of lung transplant centers throughout the world have switched their lung-preservation strategies from intracellulartype high-potassium solutions to the use of Perfadex. By improving lung tissue preservation and, ultimately, posttransplant lung graft function, prolonged ischemic tolerance in human lungs was also achieved. This point is important because the majority of patients included in the study by Novick and colleagues ${ }^{14}$ received lungs that were not preserved with highpotassium-based preservation solutions. Also, a significant portion of cases included in the ISHLT registry until today have not received low-potassium-based preserved lungs. Assuming that the concept of diminished "functional reserve" in elderly donor lungs is valid, this fact may explain why a negative association between donor age and ischemic time was repeatedly shown in these analyses. This study is the first to focus specifically on the impact of lung donor age on posttransplant outcome in the low-potassium-based lung preservation era. We were not able to show differences in pulmonary function tests in our patients. In the early perioperative period and during the first year after transplantation, the $\mathrm{FEV}_{1}$ and best $\mathrm{FEV}_{1}$ measures between groups were almost identical. Thus, our study does not underline the theoretically reported diminished "functional reserve" in elderly lung grafts. This finding could further be an effect of better lung preservation with low-potassium dextran, in that the lower functional reserve in elderly lung grafts is better preserved.

From the molecular standpoint, the discussion around the use of elderly donor lungs for transplantation should certainly include the different mechanisms of brain death. As shown in this study the majority of donors in the elderly cohort died of cerebrovascular accidents, whereas more donors in the younger cohort died of head injury. The type of brain death and the neurohumoral and biochemical changes that occur with brain death are different in a patient whose death was caused by trauma and a patient whose death was the result of cerebrovascular accident. It is possible that the cause of brain death will become even more relevant with increasing use of elderly donor organs in the future. The relationships between the outcome after transplantation of elderly lungs and the mechanisms of brain death should be investigated in future work and cannot be explained in this study.

In summary, there is still intense debate ongoing about the impact of donor age on outcome after lung transplantation. We found that the short- and long-term outcomes are similar after transplantation of lungs from donors 50 years of age and older compared with that after transplantation of lungs from younger donors. It is important to note that all lungs in this study were preserved with a low-potassiumbased preservation solution (Perfadex). On the basis of the findings in this study, we recommend that acceptability criteria for donor lungs should be reassessed with regard to "elderly" donor organs. It is not clear whether older donor lungs may have beneficial or detrimental effects on overall outcome after lung transplantation. A beneficial effect could be a decline in immune function leading to lower susceptibility to rejection. A detrimental effect could be reduced lung function because of subclinical emphysematous changes or an increased susceptibility to certain cancers. Because this is not clear, lungs from elderly donors should only be transplanted after careful selection. No other evaluation parameter except for donor age should be out of "traditional limits" when elderly organs are evaluated for lung transplantation.

We thank Mrs. Petra Oppelt for data review and analysis as a professional biostatistician. Mrs. Kerstin Meyer, MS, has significantly contributed to collecting and analyzing data in this study.

\section{References}

1. Fischer S, Strueber M, Haverich A. Current status of lung transplantation: patients, indications, techniques and outcome. Med Klin. 2002; 97:137-43.

2. Trulock EP, Edwards LB, Taylor DO, Boucek MM, Mohacsi PJ, Keck BM, et al. The Registry of the International Society for Heart and Lung Transplantation: Twentieth official adult lung and heartlung transplant report-2003. J Heart Lung Transplant. 2003;22: 625-35.

3. Hosenpud JD, Bennett LE, Keck BM, Edwards EB, Novick RJ. Effect of diagnosis on survival benefit of lung transplantation for end-stage lung disease. Lancet. 1998;351:24-7.

4. Waddell TK, Peterson MD. Lung transplantation. Xenotransplantation. Chest Surg Clin N Am. 2003;13:559-76.

5. Lick SD, Zwischenberger JB, Alpard SK, Witt SA, Deyo DM, Merz SI. Development of an ambulatory artificial lung in an ovine survival model. ASAIO J. 2001;47:486-91.

6. Steen S, Sjoberg T, Pierre L, Liao Q, Eriksson L, Algotsson L. Transplantation of lungs from a non-heart-beating donor. Lancet. 2001;357:825-9.

7. Dark JH. Lung: living related transplantation. Br Med Bull. 1997;53: 892-903. 
8. Pierre AF, Sekine Y, Hutcheon MA, Waddell TK, Keshavjee SH. Marginal donor lungs: a reassessment. $J$ Thorac Cardiovasc Surg. 2002;123:421-7.

9. Strueber M, Wilhelmi M, Harringer W, Niedermeyer J, Anssar M, Kunsebeck A, et al. Flush perfusion with low potassium dextran solution improves early graft function in clinical lung transplantation. Eur J Cardiothorac Surg. 2001;19:190-4.

10. Fischer S, Matte-Martyn A, De Perrot M, Waddell TK, Sekine Y, Hutcheon M, et al. Low-potassium dextran preservation solution improves lung function after human lung transplantation. J Thorac Cardiovasc Surg. 2001;121:594-6.

11. Hertz MI, Taylor DO, Trulock EP, Boucek MM, Mohacsi PJ, Edwards LB, et al. The registry of the international society for heart and lung transplantation: nineteenth official report-2002. J Heart Lung Transplant. 2002;21:950-70.

12. Orens JB, Boehler A, de Perrot M, Estenne M, Glanville AR, Keshavjee S, et al. A review of lung transplant donor acceptability criteria. J Heart Lung Transplant. 2003;22:1183-200.

13. De Meester J, Smits JM, Persijn GG, Haverich A. Listing for lung transplantation: life expectancy and transplant effect, stratified by type of end-stage lung disease, the Eurotransplant experience. J Heart Lung Transplant. 2001;20:518-24.

14. Novick RJ, Bennett LE, Meyer DM, Hosenpud JD. Influence of graft ischemic time and donor age on survival after lung transplantation. J Heart Lung Transplant. 1999;18:425-31.

15. Smits JM, Mertens BJ, Van Houwelingen HC, Haverich A, Persijn GG, Laufer G. Predictors of lung transplant survival in Eurotransplant. Am J Transplant. 2003;3:1400-6.

16. Hosenpud JD, Bennett LE, Keck BM, Boucek MM, Novick RJ. The Registry of the International Society for Heart and Lung Transplantation: eighteenth Official Report-2001. J Heart Lung Transplant. 2001;20:805-15.

17. Meyer DM, Bennett LE, Novick RJ, Hosenpud JD. Effect of donor age and ischemic time on intermediate survival and morbidity after lung transplantation. Chest. 2000;118:1255-62.

18. Bhorade SM, Vigneswaran W, McCabe MA, Garrity ER. Liberalization of donor criteria may expand the donor pool without adverse consequence in lung transplantation. J Heart Lung Transplant. 2000; 19:1199-204. 